\title{
The Use of DSS/EIS for Sustainable Development in Developing Nations
}

\author{
Sherif Kamel \\ The American University in Cairo, Egypt \\ skamet@aucegypt.edu
}

\section{Abstract}

The use of information technology over the last two decades has been growing in different sectors and industries tackling many issues in the economy and penetrating many aspects of decision-making and organizational development. Information and communication technologies are also seen as a building block that can support socioeconomic development. Therefore, nations around the world have been attempting to capitalize on the capacities of various information and communication technologies to support their planning, development and growth processes. Egypt, as a developing country, attempted since the mid 1980 s to invest in its information infrastructure and focus on the development of information and management support systems to leverage the decision making process in the government and the public sector with an emphasis on its local administration using management support systems such as decision support systems and executive information systems for socioeconomic development objectives. Following is the outcome of a research conducted covering the GIDSC project, sponsored by the government, and aiming to leverage the decision making process for governors. (This paper is partially based on a research conducted in 2001 by Yosra Gadallah on the use of advanced information systems applications in the decision making process at the public administration level in Egypt.)

Keywords: Developing Nations, Egypt, EIS, DSS, Sustainable Development

\section{Introduction}

Until recently, information itself was not considered an important asset for the firm, whereas the management process was considered a face-to-face, personal art and not a global communication process. Today, however, it is understood that information systems are essential for managers because most organizations need it to survive and grow (Laudon and Laudon, 2000). Moreover, the vitality of information technology is greatly emphasized in most developing countries (Goodman, 1991; Lind, 1991) where governments have played a key role in its diffusion to support developmental purposes (Moussa and Schware, 1992). Government of developing nations, through policies, laws and regulations, do exert the largest influence throughout various organizations and entities in terms of technology and innovative processes deployment (Nidumolu and Goodman, 1993). Recently, the extensive benefits of information collection, analysis and dissemination, supported by computer-based technologies have been sought to enable decision makers and development planners to accelerate socioeconomic development programs. Thus, many

Material published as part of these proceedings, either on-line or in print, is copyrighted by Informing Science. Permission to make digital or paper copy of part or all of these works for personal or classroom use is granted without fee provided that the copies are not made or distributed for profit or commercial advantage AND that copies 1) bear this notice in full and 2) give the full citation on the first page. It is permissible to abstract these works so long as credit is given. To copy in all other cases or to republish or to post on a server or to redistribute to lists requires specific permission from the publisher at Publister@intommingscience.org developing nations have been embarking on medium and large-scale information technology and computerization projects to leverage its developmental processes. In practice, most of these projects have sought to introduce computer technologies to realize socioeconomic development. However, frequently, it concentrated more on large scale capital expenditures rather than on human capital invest- 
ment such as training and human resource development (UNESCO, 1989), and therefore, failed to achieve its goals resulting in a generally negative conventional wisdom which defined information technology as inappropriate to developing countries.

Respectively, developing nations, gaining from the experiences of the past, have been extensively investing in training, consultation and the establishment of a strong and efficient information and technology infrastructure that could move them into a state of self-sufficiency and help build a national information infrastructure that could help boost socioeconomic development. However, to realize concrete benefits from the implementation of information technology, there is an ultimate need to apply the appropriate technology that do fit the country's values, social conditions and cultural aspects as well as the identification of information technology needs, and its related policies and regulations that could provide the proper environment for its implementation.

Realizing the enormous impact of information technology and its vital role in socioeconomic development, the government of Egypt has been striving to implement a nation-wide strategy to support the realization of its targeted objectives. Therefore, it adopted since the mid 1980s a supply-push strategy to improve Egypt's managerial, administrative and technological infrastructure. The objective was to introduce and diffuse information technology into all ministries, governorates, and government organizations, which necessitated the development of an infrastructure for infomatics and decision support, a software service industry and a high-tech industrial base in the areas of electronics, computers and communications. Consequently, the government, late in 1985, established the Cabinet, Information and Decision Support Center (IDSC) to support the Cabinet and top policy makers in key socioeconomic issues through the formulation of information and decision support projects. One of such projects was the Governorates Information and Decision Support Systems Project (GIDSC) to cover Egypt's 27 provinces. The essence of this research is to study the methodology with which DSS/EIS are applied through the GIDSC project in supporting governors to make better utilization of their resources and improving their decision making processes while adding to their autonomy and saving both time and effort.

\section{Literature Review}

Decision support systems (DSS) imply the use of computers to assist managers in their decision processes in semi and ill-structured tasks, support rather than replace managerial judgment, and improve the effectiveness of decision making rather than its efficiency (Keen and Scott Morton, 1978). Such systems are developed to support the monitoring, controlling, decision-making and administrative activities of senior managers (Laudon and Laudon, 2000). Literature shows that decision support systems were mainly developed and applied in profit-oriented organizations, which are managed through market constraints and trends. However, IDSC experience suggests new areas of applications for decision support systems which are based on developmental objectives for socioeconomic improvement, governed by country-wide laws and regulations and regarded as systems which ought to fit within developmental contexts, policy decision making and supporting management problem solving. It also proved, through over 600 projects that guided by a social context, cultural and organizational norms; decision makers select information processes to aid them to realize the optimal utilization of their scarce resources. Moreover, given the proper problem formulation, and analysis of available information, decision support systems help decision makers formulate scenarios and options for courses of action with respect to different decisions (Thierauf, 1991).

While there are examples of successful decision support systems used for strategic decision making by top management in such decision contexts as mergers and acquisitions, plant location and capital expenditures, these systems tend to focus on limited and well-structured phases of specific decisions. However, when supporting the comprehensive strategic decision making process over a longer span of time with competing and changing strategic and socioeconomic development issues, multiple decisions and chang- 
ing participants, much less progress has been made. A large part of the challenge comes from the messy, complex nature of the strategic decision making process and the related issues that it brings to the design, development and implementation of decision support systems. This could be attributed to the nature of strategic decision making which is usually murky, ill structured and drawn out over a long period of time through requiring rapid response capabilities in crisis situations (El Sherif and El Sawy, 1988). It is usually a group rather than an individual effort involving cooperative problem solving, crisis management, consensus building and conflict resolution (Gray, 1988). Moreover, it involves multiple stakeholders with different assumptions (Mason and Mitroff, 1981). The information used is mostly qualitative, verbal and poorly recorded (El Sherif and El Sawy, 1988) and its unlimitedness causes not only an information overload with multiple and conflicting interpretations but also the absence of relevant information (Zmud, 1986). Finally, the formation of strategic decisions is more like an evolving and emerging process where the supporting requirements are difficult to forecast.

There are also some challenges that are associated with the nature of the decision maker such as difficulty in contacting due to his valuable time, unwillingness to spend time learning, preference to rely more on personal experience and intuition rather than on information technology tools and techniques, and resistance to changes. It is also important to note that DSS are usually described as soft technologies, because the determinants of success and failure depend on non-technical factors such as problem orientation, its evolutionary approach to system design and the system analyst working as process consultant rather than provider of solutions (Holthman, 1992). As for executive information systems (EIS), in recent years several governments were tempted to apply EIS in public sector organizations in an attempt to aid government executives in their decision-making processes and the GIDSC case represents a practical demonstration for such implementation. In that sense, EIS aid executives in their decision-making processes by allowing them to gain more access to information in less time and effort using advanced technologies in extracting information and using analysis techniques (Thierauf, 1991).

There are a variety of internal and external pressures that might motivate an organization to develop an EIS, it could be servicing debt, dissatisfaction with existing reporting system, improving quality or increasing revenues (Watson, Houdeshel and Rainer, 1997). Similar to other computer based information systems EIS consists of the interaction of several elements which are people, procedures, information and technology i.e. hardware and software (Kroenke and Hatch, 1994). For example in the case of GIDSC, the people element played a major role since its inception, the managers and the staff behind the spread and application of the project played most of the interpersonal informational and decisional roles. According to interviews conducted with senior executives involved with the project, it was clear that it was first introduced to the governorates through a group of former high-ranked army officers who played interpersonal roles by becoming the link between IDSC and the governors who they maintained very good relations with in order to convince them of applying the project in their governorates. They played informational roles by acquainting the governors with the importance of information centers and the application of information systems that would aid them in their decision-making processes. The decisional roles were played, for example, in cases of crises facing the project where they would handle the problems and attempt to find out solutions.

In terms of procedures, the GIDSCs' EIS was tailored to suit the needs of the executives using the system. Data was obtained and processed into information following a set of procedures that was then sent to government executives in the form of brief reports. As for information it was collected using patterned questionnaires where definitions of required information are referred back to a data dictionary -published by IDSC and periodically updated- in order to avoid confusion of overlapping terms that might lead to false or unreliable information. With respect to technology, it was not the most advanced due to the limited budget of the project; however, the essence was not to apply state-of-the-art technology but rather what was more appropriate to do the job with minimum costs. 
Several studies were conducted to test the implementation of EIS in the public sector and government owned organizations since they were originally developed for profit-oriented private companies (Hasan and Hasan, 1997). According to a study conducted in the U.S. on more than 300 companies aiming to discover the differences between private and government EIS, some interesting findings were discovered. For example, it is more difficult to shift funds from one account to another in a government EIS; also it is more difficult to justify the cost of developing a government owned EIS. Moreover, a government organization might have greater difficulty in measuring the output of its EIS and more severe data problems to solve when building its EIS, Those differences were related to environmental, organizational, transactional, structural and procedural factors (Watson and Carte, 2000).

Another study was conducted in Australia showed that EIS give managers a more accurate picture of the organization's performance and provide support for improved strategic benefits not only for managers but also for the rest of the organization. Based on systems designed for privately owned firms with clearly defined goals, EIS are appropriate for modern public organizations but need to be more flexible and agglomerate a wider range of capabilities and facilities than the original private sector product-oriented model (Hasan and Hasan, 1997). This might be due to the fact that public sector activities are mandatory, have broad impacts, must satisfy unique public expectations, often have vague and conflicting objectives; less autonomy and control over decision-making and personnel is more difficult (Watson and Carte, 2000).

To conclude, EIS as a concept has its successes and failure; it evolved through the years aiming to overcome its deficiencies by conducting continuous research. Same goes for the application of EIS in the public sector, it also has its achievements and defects; the Egyptian government's experience with its application of EIS and decision support systems is quite interesting with so many lessons to be learnt from the application of such technologies in public administration in a developing nation.

\section{Decision Making in Public Administration}

In one of its many attempts to overcome administrative bureaucracy and promote rational decision making, the Egyptian government since the mid 1980's started exploring opportunities provided by decision support systems and executive information systems to improve the decision making capabilities of the Egyptian Cabinet. One offspring of these attempts was the creation of the Cabinet's IDSC whose successes in decision support projects triggered the creation of other centers and units on the national level. The main goal of IDSC was to support the cabinet in its decision-making processes; later on IDSC adopted several projects on the national level to aid the country in its socioeconomic development plans.

The Egyptian Cabinet basically comprises the Prime Minister, cabinet ministers, and sectoral ministerial committees assisted by their technical and administrative staff. Decision making at the cabinet level addresses a variety of national socioeconomic and infrastructure concerns such as reducing the deficit in the balance of payments, the national budget, debt management, performance improvement of public sector organizations, promotion of small and medium scale private industries and the allocation of resources to solve urban housing problems and population growth. The decision making process of the Cabinet involves much debate and group discussions, requiring much preparation and conduct of surveys and studies and is subject to public accountability and media attention (Sprague and Watson, 1993).

In the mid 1980s, Egypt launched its economic reform plans and policies facing major infrastructure and socioeconomic development challenges. Awareness existed of the vulnerability of static plans and slow decision-making at the strategic level. It brought into focus the critical importance of making information available in an integrated form to support the decision-making process of the Cabinet through the use of the most suitable information technologies and services. And so it was in November 1985, as part of an intensive national plan for administrative development, information systems project was launched namely 
Information Project - Cabinet of Ministers (IPCOM), and through the years it evolved and developed into what is now known as the Cabinet's Information and Decision Support Center - IDSC (Sprague and Watson, 1993).

IDSC aimed from the start to provide the Cabinet with decision and information support using the most advanced management and decision-making techniques, timely information and relevant technologies. IDSC strives to respond to the evolving needs of management and decision makers serving the highest executive level of the Egyptian government. IDSC mission statement is "empowering and enhancing the decision-making process by using state-of-the-art technology and managerial support". Respectively, its objectives include: developing information and decision support systems for the Cabinet and top policy makers; supporting the establishment of end-user information and decision support centers in the different ministries and governorates; encouraging, supporting and initiating informatics projects that will accelerate Egypt's management and technological development; and, participating in international cooperation programs and agreements, particularly in the areas of information and decision support (Kamel, 1998).

IDSC started as a single project; however evolved through the years and achieved several successes with respect to different sectors and industries including legislative reform, public sector reform, financial reform, human resources development and job creation, economic reform and structural adjustment, capital goods manufacturing, commercial registration development, automation, natural resources management, building the information services industry, local development projects at the governorates level, sectors development projects at the ministerial level, civil information systems: the national ID number, technology development projects, urban planning, environmental development, and preserving the cultural heritage amongst others.

One of the major projects IDSC adopted since its initiation is the Governorates Information and Decision Support Centers (GIDSC), which basically aims at improving administrative, managerial and technological effectiveness locally. The main objective of the project was decentralizing the decision making process and producing accurate, timely and reliable information feasible for top executives; the governors. The GIDSC project went through different phases since its launch in 1987 targeting the coverage of Egypt's 26 governorates and with a plan ending in 2002 to cover all cities and villages in the nation.

\section{Case: The GIDSC Project}

In one of the Egyptian Government's attempts to introduce and diffuse information technology plus seek more decentralization and less bureaucracy, it created the Governorates and Information Support Centers (GIDSC) project. The project developed enormously from a simple idea in the early 1980s until it reached full growth aiming to cover all Egypt in the late 1990s. It passed through several phases until it reached its current status witnessing opposition from bureaucrats and government authorities that found power in acquiring information and the mere thought of decentralizing it meant loss of authority.

The environment of the GIDSC was that of the public sector, run and operated by bureaucrats and politicians. The concept of power in such an environment was represented in the acquisition and possession of information. This represented a barrier to the GIDSC which its core concept is based on sharing information aiming to decentralize the decision making process of government executives by diffusing the concept of informatics and creating information centers to the public. In order to overcome such barriers the introduction of the new ideology of information sharing had to be introduced gradually via elements in the government -i.e. senior executives who do not believe in overprotecting information and are advocates of the new ideology- that bureaucrats listen to in order to gradually change the organisational culture that has been dominating the Egyptian public sector for years and that could represent major resistance to the application of information systems that depend essentially on availability of information. 
As indicated by the CEO of the project, its main goal since they first started the project was to enhance the decision making process of each governorate by providing accurate, reliable and timely information to the local executives and policy makers in each governorate. He indicated that the governors before the establishment the GIDSCs did not have the required information or a reliable source to base their designs on. Each GIDSC aimed at providing information and decision support services to various decision makers at the governorate level in order to achieve socioeconomic and development targets, supporting local agencies and authorities affiliated with the governorate to establish and develop information units and department, supporting the creation of a comprehensive information-based system at the governorate level and preparing each governorate with relevant information infrastructure required for the development of the governorates-wide information network.

Before the establishment of the GIDSCs, each governor would typically obtain his information from various administrative units and directorates (i.e. local offices of central ministries) that formed part of the governorate administration. A statistics unit located in the governorate was charged with summarizing and synthesizing such information from various sources but was ill equipped to do so because it lacked computing or networking support, which left the governor at a disadvantage while interacting with other governorates. As a result the governor's decision-making process became mostly based on intuition and adhoc decisions (Nidumolu, Goodman, Vogel and Danowitz, 1996). Thus, in order to overcome such barriers faced by governors in their decision-making process, the GIDSCs were established. However, it took a presidential decree to trigger the establishment of information centers in Egypt, which was issued on November $4^{\text {th }}, 1981$, number 627 , indicating that all governorates and central government agencies are to align their information collection, analysis and dissemination techniques through the establishment of Governorate Information and Documentation Centers (GIDC).

However, no significant impact was realized out of the decree. It was true that all governorates and government agencies followed the decree by establishing information and documentation centers but the fact was that all they did was the allocation of a room with a computer and instead of having top calibers working in the center; the worst employees were recruited becoming the resort of low-performing government staff. There were no systematic processes implemented to collect information for local administration because it was viewed as personal property and sharing it with other members, even the governor, meant a loss of power and authority. Therefore, due to the lack of coordination between the local administrations, subjectivity of its directors, and the lack of alignment between them and the governor, governors still based their decisions on intuition and adhocracy.

In 1987, the GIDSC project was launched and based on the new structure; the GIDSC became an administrative unit within the governor's office and falling in the scope of work the governor's secretary and following the policies and priorities set by the governor (Kamel, 1998). The pool of technical and managerial talents developed and available at the Cabinet's IDSC formed the basis for initiating the project, ensuring that no external expertise would be needed for its implementation and that all technical resources would be used from IDSC and the local authorities as for the managerial expertise, it was drawn primarily from former high-ranking officers in the Egyptian army, who maintained their extensive contacts with bureaucrats and politicians in the government (Nidumolu, Goodman, Vogel and Danowitz, 1996).

The first prototype was in the governorate of Suez and the center included the units of statistics, decision support, computer resources, library and publications. They all reported to the director of the center who is basically responsible for coordinating activities between the five units, preparing monthly plans, communicating with the governor, the general secretary and head of the local administration for issues concerning the center. Thus, the director's role represented the communication channel between the governor and the center, where he receives decision support requests and respectively gathers information to provide support for the governor with respect to such requests. On average the number of staff per GIDSC was ranging from 19 to 26 basically selected from local resources as part of a scheme to infiltrate IT 
knowledge within the governorate. They were composed of a combination of freshly technical and nontechnical graduates coupled with experienced administrative and bureaucratic personnel.

According to the division of responsibilities of each unit, the statistics unit was responsible for collecting data about the governorate; the decision support unit was responsible for analyzing and solving problems presented to the center by the governor or other executives, the unit was also expected to undertake problem analysis on its own initiative. The computer resources unit was responsible for storing and maintaining information in its information bases, and for developing and maintaining any software programs used by the GIDSC (Nidumolu, Goodman, Vogel and Danowitz, 1996). The library unit was responsible for storing manuals and procedures, keeping records of all works published by the GIDSC such as newsletters or any other publications and having hard copies of the data stored in the computer resources unit's databases. Finally, the publications unit played a major role in describing the centers' activities to the users, other centers and the Cabinet's IDSC. It publishes -to assure standardization between all centers- a manual to be placed in all centers that stated the steps to be taken to establish a center, its mission, goals to be achieved, objectives and targets- and a monthly newsletter in Arabic, highlighting the centers' solution to problem areas that were identified by the Cabinet's IDSC as discussion topics of the month (Nidumolu, Goodman, Vogel and Danowitz, 1996).

During the first couple of years most governors were a bit skeptic concerning the value of information systems or decision support centers. They even doubted the benefits promised by the project. In the first two years only seven out of twenty- six governorates joined the project and were convinced to establish their own centers. The following three years were even harder on the project team as they were trying to fight the resistance to technology. They overcame several barriers until they eventually covered all 26 governorates and city of Luxor by the deadline of the project, which was in the year 1992 (Nidumolu, Goodman, Vogel and Danowitz, 1996).

In 1997, the management of the project based on the request of different governors and reflecting the success of the project, decided to extend the project for another five years aiming to cover all districts, cities, villages, local administration and directories by the year 2002. Today, there are over 3000 computers in all centers linked via the GIDSC network and linking governorates, districts, cities, villages, directories and local administrations.

\section{The Application of EIS/DSS in the GIDSC Project}

The GIDSC project aimed at supporting the decision making process of the governors and senior government executives by decentralizing the collection, storage and analysis of information in each governorates' center. The objective was to provide executives with easy access to information that is relevant to their decision making process. Respectively, an EIS seemed appropriate for realizing that objective. In the case of the GIDSC, due to the limited resources, the EIS used comprised a hybrid model of computerbased and manual interfaces.

With a closer look at the decision making process of the governor, one can realize that usually the governor sends for information requests to various authorities and organizations. Respectively and based on such requests, with the support of the GIDSC, information is gathered, analyzed, and compiled in a way to provide a comprehensive overview for the governor. Sometimes, the GIDSC develops, if possible, forecasts and predictions about future trends. Upon the compilation of the information, it is sent to the governor in the form of recommendations and decision alternatives to help him optimize the decisionmaking processes. It is important to note that the sectoral database developed and compiled by the GIDSC feeds such recommendations and alternatives with up-to-date accurate information; the sectoral database represents the computer-based segment of the EIS. Each GIDSC compiles its own information through interviews, questionnaires, surveys and researches and then it is compiled on a more aggregate form that 
The Use of DSS/EIS for Sustainable Development

feeds the main IDSC at the Cabinet level. It is important to note that information flows between all centers continuously to ensure that it is always updated, timely and reliable.

Information requests coming to the GIDSC could take more than one form and that could include either information requests on periodic basis, usually monthly, in the form of newsletters and reports or information requests related to a high priority unscheduled issue that has developed. Pending on the type of information required, the information flow within the GIDSC takes its form.

The computer-based segment of the EIS is focused in the sectoral databases located in the computer resources unit (CRU) where the flow of information between units starts with data collection (both primary and secondary data). The statistics unit (SU) collected the primary data with respect to each sector via patterned questionnaires; however, the consistency of the data collected is a major issue that was and still is facing the data collection process. Therefore, to overcome such a problem a data dictionary was created, published and periodically updated so when information is requested concerning a specific sector, the centers' staff refers back to the dictionary to identify accurately what is required. As for the secondary data, it is collected by the documentation and library unit (DLU) where all manuals, regulations and procedures of the center as well as studies developed and published by the center, such as newsletters or any other publications, and hard copies of the data stored in the CRU are located. The outputs from both SU and DLU represent the raw data that goes into the CRU where they are processed into the databases in the framework of tables, forms, queries and reports. Based on the request type the report is identified. If it is a periodic report, the output of the CRU could be in the form of processed data - information going to the PU. However, if it is a special or an ad-hoc report, queries go to the decision support unit (DSU). The outcome reaches the governor's office in the form of analyzed information coupled with suggestions and proposals for decisions to be taken.

Based on the use of the GIDSC EIS, there were a number of cases where the system was extremely useful and that includes as examples:

- Supporting many governorates in developing job allocation plans for returning expatriates from the Gulf States.

- Developing a health plan for vaccination for newly born babies through the formulation of a fiveyear development plan.

- Formulating in the cases of the governorates of Port Said, Suez and Cairo a strategy concerning housing allocation by computerizing thousands of incoming housing requests leading to saving an estimated total of 600000 US dollars.

- Identifying and optimizing the allocation of a number of resources including water as well developing strategies in a number of sectors including tourism, agriculture and electricity.

Using a SWOT analysis to identify the capacities of the GIDSC EIS, it is important to note the following findings:

In terms of strengths;

- Increasing ease of access to information for government executives.

- Creating nation-wide sector-based databases to facilitate the process of information gathering and retrieval.

- Developing and adapting information systems to the local administrations' requirements while committing to the budgetary and resources constraints and limitations.

- Formulating manuals and data dictionaries to standardize the requirements and objectives of all centers to have consistency within the mission, goals and responsibilities. 
- Using local calibers to work on the project being more aware of the surrounding circumstances and the resources required.

- Developing a user-friendly interface to facilitate its use by local executives and that caters to their personal requirements.

In terms of weaknesses;

- Information is still treated as power that is very hard to get access to causing some negative impacts on the project that mainly relies on the concept of information sharing.

a The GIDSC EIS is not fully automated resulting sometimes in information delay to executives reflecting negative implications on the efficiency of the system due to the time factor.

- Most of the information related to the processes of the project and its updates are not documented making maintenance a difficult task.

- Benefits of the system are difficult to measure since they are mostly intangible in the form of time saved, and efforts rationalized.

- Bureaucracy and red tape leads to delays and inefficiencies.

In terms of opportunities;

- Establishing more training centers to create local calibers which can also help create more technical skills that could lead to offering them better job opportunities and decrease unemployment rates.

- Connecting the all centers to the World Wide Web could aid executives in obtain information on external elements and factors in a few seconds that could affect the operation of their systems.

a The system could help governors and executives better use their time in focusing on formulating development and socioeconomic plans.

- Networking all sectoral databases could be helping develop the infrastructure for the eGovernment project.

In terms of threats;

- Sectoral databases need to be regularly updated or the information contents will become obsolete and hence affecting the support provided to the decision making process of governors and/or other local executives.

- The flow of information from an automated system to a manual system could affect the robustness of the information contents due to the involvement of human element in the manual system.

- The cost of establishing a GIDSC that is relatively high can push executives to be more reluctant to venturing into that project especially that benefits are not be expected before the end of the first year.

- The GIDSC information should be properly documented and should not be solely depending on individuals and they should be available in both soft and hard copies for proper maintenance and updating.

\section{Conclusion}

Developing countries represent a challenging domain for information and decision support systems. The characteristics of the country, the problems faced and the opportunities are among the challenges. Examples of these challenges include: the lack of informatics infrastructure, the use and availability of informa- 
The Use of DSS/EIS for Sustainable Development

tion is still limited, the lack of technical expertise and the application gap between existing information and decision support systems innovations is widening. Moreover, the experience of GIDSC with regard to the development and implementation of large information and decision support systems projects helped identify new challenges.

These challenges relate to: strategic decision-making, decision support systems, executive information systems and its implementation. These challenges related to the ill-structured nature of processes extending over long periods of time, the involvement of many stake holders, the need for conflict resolution, consensus building and crisis management, the efficient and effective use of scarce resources, and the turbulent and dynamic environment in which the decision making process occurs. It also relates to successfully managing the development of multiple information and decision support systems, their institutionalization within their application contexts, and the development of appropriate interfaces. Moreover, it relates to the lack of user involvement, resistance to change, lack of top management support, lack of vital continuous communication, poor documentation, and language problems (Gass, 1987).

\section{Lessons Learnt}

- Structuring of issues is an integral part of the design and implementation of DSS/EIS when dealing with socioeconomic development.

- Providing DSS/EIS requires much time and effort in building and integrating databases from multiple data sources and sectors.

\ Developing DSS/EIS for one socioeconomic issue might affect other issues.

- Prototyping DSS/EIS should be reflected during the design, development and delivery phases.

- Recurring decisions related to certain issues need to be monitored through a management system for tracking such changes.

- Successfully designing and delivering DSS/EIS is based upon top management support during implementation and organizational support during institutionalization.

- Evaluating DSS/EIS is a vital process that should accompany all phases of implementation and institutionalization.

\section{References}

El-Sherif, H and El Sawy, O. (1988). Issue-based decision support systems for the Cabinet of Egypt. MIS Quarterly 12(4), 551569.

El-Sawy, O (1985). Personal information systems for strategic scanning in turbulent environments: Can the CEO go on-line? MIS Quarterly 9(1).

Gass, S (1987). Operations research-supporting decisions around the world. Operational Research, G.K. Rand (eds.) Amsterdam: Elsevier Science Publishers.

Goodman, S.E (1991). Computing in a less developed country. Communications of the ACM, 34 (12).

Gray, P (1988). Using technology for strategic group decision making, working paper, Claremont Graduate School.

Hasan, H and Hasan, S. (1997). Computer-based performance information for executives in local government. Australian Journal of Public Administration, 56(3), 24-29.

Holtham, C (1992). Executive information systems and decision support systems. London: Chapman.

Kamel, S (1998). Decision support systems and strategic decision making in Egypt in information Systems for Pubic sector management: working paper series. Manchester: Institute for Development Policy and Management, July. 
Keen, P.G.W and Morton, M.S. (1978). Decision support systems: an organizational perspective. Reading: Addison-Wesley Publishing Company.

Kroenke, D and Hatch, R. (1994). Management information systems. New York: McGraw.

Laudon, K and Laudon, J. (2000). Management information systems: organization and technology in the networked enterprise. Upper Saddle River: Prentice.

Lind, P (1991). Computerization in developing countries: models and reality. London: Routledge.

Mason, R.O and Mitroff, I. (1981). Challenging strategic planning assumptions. New York: John Wiley \& Sons.

Moussa, A and Schware, R. (1992). Infomatics in Africa: lessons from World Bank experience. World Development. 20 (12).

Nidumolu, S.R and Goodman, S.E (1993). Computing in India: an Asian elephant learning to dance. Communications of the $A C M, 36(4)$.

Nidumolu, S.R., Goodman, S.E., Vogel, D.R. and Danowitz, A.K (1996). Information technology for local administration support: the governorates project in Egypt. MIS Quarterly, 20 (2).

Sprague, Ralph M. Jr., and Watson, H. J. (1993). Decision support systems: putting theory into practice. Englewood Cliffs: Prentice.

Thierauf, Robert J (1991). Executive information systems: A guide of senior management and MIS professionals. New York: Quorum.

United Nations Educational, Social and Cultural Organization (1989). World Communications Report. Paris: United Nations Press.

Watson, H., Houdeshel, G., and Rainer, R.K., Jr (1997). Building executive information systems and other decision support systems. New York: John Wiley and Sons.

Watson, H, and Carte, T.A. (2000) Executive information systems in government organizations. Public Productivity and Management Reviews, 23(3), 371-382.

Zmud, R.W (1986). Supporting senior executives through decision support technologies: A review and directions for future research. Decision support systems: a decade in perspective. E.R. McLean and H.G. Sol (eds.). Amsterdam: Elsevier Science Publishers.

\section{Biography}

Sherif Kamel is an assistant professor of management information systems at The American University in Cairo in the Management Department at the School of Business, Economics and Communication. He was the director of the Regional IT Institute during the period [1992-2001]; one of Egypt's leading executive development organizations. During the period 1987-1992, he worked at the Cabinet of Egypt Information and Decision Support Center where he co-established and managed its training department. Dr Kamel designs and delivers professional development programs in various information systems management and applications for public and private sector organizations. He has formulated a large number of training alliances and partnerships and has conducted many training programs for organizations in Africa, Asia, the Middle East and Europe. In 1996, he was one of the co-founding members of the Internet Society of Egypt. He has published in IT transfer to developing countries, electronic commerce, human resources development, decision support applications and knowledge management. He serves on the editorial and review boards of a number of information systems and management journals and is the associate editor of the Annals of Cases on Information Technology Applications and Management in Organizations. Dr Kamel is currently the VP for Communications for the Information Resources Management Association (IRMA) and academic advisor for the Regional IT Institute. He is a graduate of London School of Economics and Political Science (UK) and The American University in Cairo (Egypt). 